\title{
Y a-t-il une rhétorique romantique ? Enseignement et pratique de l'éloquence (1800-1830)
}

Is There a Romantic Rhetoric? Teaching and Practice of Eloquence (1800-1830)

\section{Marta Sukiennicka}

\section{OpenEdition}

\section{Journals}

Édition électronique

URL : https://journals.openedition.org/recherchestravaux/4024

DOI : 10.4000/recherchestravaux.4024

ISSN : 1969-6434

Éditeur

UGA Éditions/Université Grenoble Alpes

Édition imprimée

ISBN : 978-2-37747-326-7

ISSN : 0151-1874

Référence électronique

Marta Sukiennicka, «Y a-t-il une rhétorique romantique? Enseignement et pratique de l'éloquence

(1800-1830) », Recherches \& Travaux [En ligne], 99 | 2021, mis en ligne le 08 décembre 2021, consulté le 11 décembre 2021. URL : http://journals.openedition.org/recherchestravaux/4024 ; DOI : https:// doi.org/10.4000/recherchestravaux.4024

Ce document a été généré automatiquement le 11 décembre 2021.

(C) Recherches \& Travaux 


\title{
Y a-t-il une rhétorique romantique? Enseignement et pratique de l'éloquence (1800-1830)
}

Is There a Romantic Rhetoric? Teaching and Practice of Eloquence (1800-1830)

\author{
Marta Sukiennicka
}

1 Le célèbre mot d'ordre de Victor Hugo "Guerre à la rhétorique ${ }^{1}$ " a longtemps permis d'entretenir le mythe d'une littérature romantique privée de tout lien avec la rhétorique classique. En outre, la thèse de Gérard Genette sur la rhétorique restreinte à l'elocutio ${ }^{2}$ a contribué à privilégier l'approche uniquement stylisticienne de l'ancien empire de l'éloquence, comme si les autres parties de l'art oratoire (inventio, dispositio, memoria, actio) ne fournissaient plus matière à la réflexion des rhétoriciens au $\mathrm{XIX}^{\mathrm{e}}$ siècle. Or, Françoise Douay, Arlette Michel et Anne Vibert ont prouvé que tout au long du XIX ${ }^{e}$ siècle, l'enseignement de la rhétorique ne se limitait ni à l'apprentissage des figures de style, ni à la grammaire générale ${ }^{3}$. Après la période d'une profonde remise en cause de la pédagogie rhétorique pendant les Lumières ${ }^{4}$, couronnée par une brève suppression du cours de rhétorique pendant la Révolution ${ }^{5}$, l'art oratoire connaît une véritable renaissance dans les premières décennies du XIX ${ }^{\mathrm{e}}$ siècle. La réflexion sur les divers genres de l'éloquence - l'épidictique, le délibératif et le judiciaire continuait à structurer les traités rhétoriques pendant que leur mise en œuvre informait la réalité discursive - que ce soit au barreau, à la chaire, à la tribune ou encore dans d'autres lieux où s'exerçait l'éloquence au XIX siècle (la presse, les universités, mais aussi les cafés, les clubs et la rue ${ }^{6}$ ).

2 La première génération des écrivains romantiques a redéfini l'éloquence à la fois comme pratique littéraire, philosophie du langage et action politique ${ }^{7}$. Le renouveau de l'art oratoire auquel ils ont contribué a été possible grâce à la parfaite maîtrise de l'ancienne rhétorique que ces écrivains ont pu acquérir à l'école, sous l'Empire et la Restauration. Néanmoins, en bons romantiques contestataires et rebelles, ils caricaturaient cet apprentissage dans leurs œuvres, surtout aux alentours de la fameuse bataille d'Hernani qui les opposa aux tenants d'un classicisme qu'ils jugeaient 
sclérosé. Si la reconnaissance de filiation avec la rhétorique passe chez Hugo, Balzac et Nodier par une production d'images caricaturales de leurs professeurs, elle n'en mène pas moins à une redéfinition de l'éloquence. Sa meilleure formulation est à trouver dans l'œuvre de Charles Nodier, romantique et professeur de rhétorique, auteur d'un Cours de belles-lettres (1808) et du Dernier Banquet des Girondins (1833). Son œuvre de critique et de littérateur témoigne que l'alliance de la rhétorique et du romantisme a été non seulement possible, mais aussi essentielle pour l'avènement de la modernité littéraire.

\section{Les romantiques et leurs professeurs d'éloquence}

Le même constat ressort de l'étude de nombreuses biographies des romantiques : Hugo, Vigny, Balzac et Musset ont reçu une éducation rhétorique très solide. Sous l'Empire et la Restauration - qui correspondent à l'âge de formation des futurs écrivains - on a repris les manuels et les méthodes de l'Ancien Régime. Le programme de la classe de rhétorique prévoyait l'étude des auteurs antiques comme Démosthène, Cicéron, Tacite et Quintilien, et dans la section des modernes : Bossuet, Corneille, Racine, Massillon et Fénelon ${ }^{8}$. La plupart des futurs romantiques furent des élèves brillants. Ils tentaient leur chance dans des concours pour le prix d'éloquence, comme Balzac, qui se prenait pour un "second Cicéron ${ }^{9}$ ", mais aussi pour le prix de dissertation latine, comme Musset, qui reçut le prix de la main de l'évêque Frayssinous, ministre de l'Instruction publique $^{10}$. Hugo, quant à lui, traduisait couramment Plutarque, Virgile et Tacite dès l'âge de dix ans et se targuait de mieux connaître le latin que ses précepteurs ${ }^{11}$. Malgré la "fidélité militaire ${ }^{12}$ " à la littérature classique dont ils font preuve dans leur jeunesse, à l'âge adulte, les romantiques se mettront tous à caricaturer leurs professeurs d'art oratoire.

De fait, dans les années 1830, la littérature abonde en images caricaturales des rhéteurs. Balzac dans La Peau de chagrin (1831) met en scène le personnage de Monsieur Porriquet, professeur de rhétorique de Raphaël de Valentin. Ce vieillard, "vêtu de noir, maigre et ossu », qualifié de " vivante palingénésie de Rollin ${ }^{13}$ ", incarne l'étroitesse d'esprit, la grandiloquence et l'égoïsme. Venu chercher la protection de Raphaël, riche et puissant mais au bout de ses forces vitales, Porriquet l'assomme de ses amplifications et de son style boursouflé. Cependant, le prestige de la parole du vieux professeur est tel qu'il réussit à arracher un vœu à un Raphaël mourant : sa rhétorique vainc l'apathie du jeune homme esclave de la peau de chagrin qui se rétrécit avec chaque vœu. Cette saynète peut se lire de manière allégorique : entre les classiques et les romantiques, il y a un combat à mort. Le thème de rhéteurs mortifères qui persécutent les écrivains sensibles et vulnérables revient plusieurs fois sous la plume de Sainte-Beuve ${ }^{14}$ ou de Hugo. Ce dernier dépeint un maître de collège à la fois terrifiant et grotesque dans le poème "Ce qui se passait aux Feuillantines vers 1813 » :

Les tritons que Coypel groupe autour d'une conque,

Les faunes que Watteau dans les bois fourvoya,

Les sorciers de Rembrandt, les gnomes de Goya,

Les diables variés, vrais cauchemars de moine

Dont Callot en riant taquine saint Antoine,

Sont laids, mais sont charmants ; difformes, mais remplis

D'un feu qui de leur face anime tous les plis 
Et parfois dans leurs yeux jette un éclair rapide.

- Notre homme était fort laid, mais il était stupide ${ }^{15}$.

Mais ce n'est pas uniquement la personne du professeur de collège qui réveille de mauvais souvenirs chez les romantiques : c'est aussi le contenu du programme scolaire, sévèrement critiqué par Charles Nodier. C'est ainsi qu'il décrit sa propre expérience de collège :

Quand vous en aviez fini avec les Aloïdes, [...] les Labdacides, les Danaïdes, les Pélopides, les Atrides et les autres dynasties malencontreuses, fatalement vouées aux Euménides par la docte cabale d'Aristote et surtout par la rime, il ne vous restait plus qu'un parti à prendre : c'était de recommencer, et on recommençait. [...] On décernait des récompenses et des couronnes à l'heureux enfant qui était parvenu à rassembler dans sa mémoire le plus grand nombre possible de ces inepties classiques [...]. Cette méthode d'abrutissement et de dégradation intellectuelle, qui manquait rarement son effet, s'appelait l'éducation ${ }^{16}$.

Cette critique féroce, qui serait à comparer avec les pages pleines de fiel de Jules Vallès $^{17}$, sera développée dans les Recherches sur l'éloquence révolutionnaire (1833) où Nodier s'en prend ouvertement aux prix d'éloquence et à toute la culture humaniste qu'il rend responsable de la Révolution :

Les plus anciens d'entre nous rapportaient qu'à la veille des nouveaux événements, le prix de composition de rhétorique s'était débattu entre deux plaidoyers, à la manière de Sénèque l'orateur, en faveur de Brutus l'ancien et de Brutus le jeune. Je ne sais qui l'emporta, aux yeux des juges, de celui qui avait tué son père, ou de celui qui avait tué ses enfants; mais le lauréat fut encouragé par l'intendant, félicité par le gouverneur, caressé par le premier président, et couronné par l'archevêque. Le lendemain on parla d'une révolution, et on s'en étonna, comme si on n'avait pas dû savoir qu'elle était faite dans l'éducation du peuple ${ }^{18}$.

7 L'auteur revient à plusieurs reprises sur cette accusation politique des humanités classiques: elles auraient inconsciemment préparé les élèves à la violence, non seulement verbale, mais aussi réelle. Né en 1780 , Nodier a vécu la Révolution française, il y a même participé en tant qu'orateur: dès l'âge de douze ans, il harangua les membres de la Société des amis de la Constitution et loua les jeunes révolutionnaires dans une Apothéose de Joseph Barra et d'Agricola Viala ${ }^{19}$. En 1794, il fut témoin des exécutions publiques à Strasbourg ${ }^{20}$. Cette expérience politique précoce a profondément marqué l'homme et l'écrivain. Monarchiste au retour des Bourbons en 1815, il proposa toutefois une appréciation toute en nuance de l'éloquence révolutionnaire, dont les prémices sont visibles dans son Cours de belles-lettres de 1808, et qui reçoit son plein développement dans ses œuvres des années 1830 .

\section{Charles Nodier, professeur d'art oratoire}

8 Nodier est le seul romantique à avoir non seulement suivi, mais aussi dispensé un cours de rhétorique. Lui-même se forma auprès de Joseph Droz, auteur d'un Essai sur l'art oratoire (1799). Dans ce traité exceptionnel - parce qu'il prend en compte la toute récente expérience de la Révolution -, Droz fait preuve d'une attitude critique envers l'apprentissage classique de l'éloquence ${ }^{21}$. Rejetant le principe d'imitation propre à la pédagogie classique, il préconise une démarche plus naturaliste et expérimentale: l'orateur ne doit puiser ses arguments que dans son propre cœur pour haranguer ses concitoyens. S'inscrivant dans la lignée de Bernard Lamy ${ }^{22}$ et de Jean-Jacques Rousseau ${ }^{23}$, Droz a confiance en une expressivité naturelle du langage des passions. Et 
puisque son traité devait surtout servir aux jeunes orateurs de l'époque postrévolutionnaire, tout l'intérêt de Droz se concentrait sur l'efficacité de la parole politique professée de vive voix à la tribune, et non sur la beauté d'un texte littéraire. Nodier se souviendra de cette critique de la rhétorique classique dans son propre cours de 1808. C'est une source très précieuse pour les historiens de la rhétorique parce qu'on y voit le passage du classicisme au romantisme. De fait, en 1808, Nodier est déjà un romantique en herbe.

9 Tout en témoignant de sa grande érudition en la matière, Nodier ne cesse de se distancier de l'art oratoire tel qu'il a été enseigné dans les manuels. Dans son « Discours inaugural », il affirme ne pas avoir su dans sa jeunesse apprécier le beau classique :

Soit que je ne fusse point doué de ces organisations heureuses auxquelles la perception du beau et du vrai parait toute naturelle; soit que la forme de mes études et le genre de mes lectures aient usé en moi cette fleur de sentiment et de goût sans laquelle il n'y a plus ni vivacité dans la sensation, ni exactitude dans le jugement ; soit enfin que les froissements d'une vie agitée aient disposé mon cœur à ne jouir profondément que de beautés d'une espèce agreste et sauvage, il faut bien que j'avoue à ma honte que j'ai longtemps mal apprécié le beau classique ${ }^{24}$.

La naissante sensibilité romantique éloignait Nodier du beau classique en lui inculquant un certain mépris pour les règles oratoires au nom d'une éloquence libre et d'une individualité créatrice forte. Tout au long de son ouvrage, il n'a de cesse de répéter que les œuvres littéraires (y compris les morceaux d'éloquence) importent plus que les préceptes rhétoriques ${ }^{25}$. Dans le sillage de Lamy, Rousseau et Droz, Nodier pense l'éloquence en termes de langage des passions et tient les règles oratoires pour superflues. L'éloquence est selon lui « un don du ciel » qu'on ne peut guère apprendre « dans les leçons et dans les livres des rhéteurs ${ }^{26}$ ». Elle ne provient que du cœur et de la sensibilité de l'orateur dont la tâche est de communiquer ses émotions et ses convictions à l'auditoire.

11 Il y a encore d'autres aspects qui éloignent Nodier de la pédagogie classique de l'art oratoire. Influencé par le courant grammatical ${ }^{27}$, Nodier suit davantage l'ordre analytique d'une langue que la formation d'un discours : ses réflexions commencent par la description du style (elocutio) et non par la définition des buts et des moyens de l'éloquence (inventio). Quand il commente les notions rhétoriques, il manifeste sans cesse une certaine méfiance à l'égard de cette théorie qu'il juge rétrograde. Ainsi remarque-t-il au sujet de la théorie des trois genres qu'il est inutile de s'étendre sur "ces subdivisions inutiles de la vieille rhétorique ${ }^{28}$ ». De même, il fait presque abstraction d'une autre grande division au sein de la réflexion sur l'art oratoire : ses quatre parties - inventio, dispositio, elocutio, memoria - ne sont abordées qu'à travers des exemples littéraires et de manière extrêmement expéditive ${ }^{29}$. De même, l'étude poussée des figures et des tropes lui parait superflue étant donné leur omniprésence dans la langue, même la plus primitive ${ }^{30}$. Ce qu'il garde de l'ancien savoir rhétorique, c'est l'idée même d'une éloquence libre et passionnelle. D'une certaine manière, Nodier s'inscrit dans le courant antirhétorique des Lumières mais, contrairement aux Encyclopédistes ou aux Idéologues, autres grands pourfendeurs de la rhétorique classique, dans ses essais et dans sa fiction il refonde l'éloquence sur de nouvelles bases, et notamment sur la conception romantique de la parole-action. Celle-ci est souvent représentée en mode mineur, désenchantée et nostalgique d'un âge d'or de la parole politique, c'est-à-dire de la Révolution qui selon lui « ressemble à ces feux éclatants et 
colorés qui frappent de surprise et d'admiration le voyageur de nuit, mais à l'aspect desquels il s'arrête saisi d'effroi en se rappelant qu'ils décèlent un volcan ${ }^{31}$ ».

De fait, l'événement révolutionnaire fut fondamental pour cette nouvelle conception de l'éloquence ${ }^{32}$. Dans son Cours de 1808, contrairement à d'autres auteurs des cours de rhétorique qui passaient sous silence cette sanglante période de l'histoire ${ }^{33}$, Nodier ose commenter les discours de Mirabeau qu'il compare aux plus illustres orateurs anciens : "Doué de plus de grâce que Démosthène, de plus d'énergie que Cicéron et d'autant de génie que tous les deux, Mirabeau a rassemblé toutes les parties du grand orateur, excepté la vertu ${ }^{34}$. » Il passe également en revue les discours de l'abbé Maury, Cazalès, Barnave et Vergniaud, sans pour autant s'arrêter sur les différences de leurs rhétoriques. Il reviendra à ce sujet plus tard dans Le Dernier Banquet des Girondins et dans les Recherches sur l'éloquence révolutionnaire qui constituent le tome VII de ses Euvres complètes parues en 1833 chez Eugène Renduel.

\section{La topique du délibératif dans Le Dernier Banquet des Girondins}

13 Dans Le Dernier Banquet des Girondins, Nodier mobilise l'éloquence délibérative pour restituer la parole de ceux qu'il a qualifiés comme « les grandes figures historiques de [s]on enfance, les héros de la première tragédie qui eût frappé [s]es regards, les oracles de [s]a rhétorique ${ }^{35}$. »Cette œuvre relève d'un genre mixte, à cheval entre le roman et le théâtre ${ }^{36}$, et elle se rapproche le plus du modèle de symposium platonicien où les convives, débattant de sujets de grande importance, prennent la parole tour à tour, directement, sans être introduits par un narrateur ${ }^{37}$. Nodier fait revivre la parole des Girondins prononcée dans un moment bien précis de l'histoire la Révolution, dans la nuit du 30 au 31 octobre 1793, la veille de leur mort, décrétée par Robespierre ${ }^{38}$. C'est une circonstance doublement solennelle : à cause de la mort qui approche et à cause de la situation historique de la France qui bascule dans la Terreur. Nodier affirme dans la préface que, selon lui, «il n'existait rien [...] de plus magnifique dans toutes les histoires du temps passé que ce banquet des martyrs de la liberté qui devisent entre eux de leur république chérie ${ }^{39}$ ». La prison devient une tribune politique pour ces révolutionnaires passionnés d'idées républicaines mais aussi désenchantés par le cours de l'histoire qui les condamne à leur tour à la mort. Quant à la composition de l'ouvrage, Nodier minore ses mérites littéraires en affirmant que " pour les faits, c'est l'article du journal ou la relation de l'almanach; pour les discours, c'est le pastiche ; pour les dialogues, c'est le centon ${ }^{40} »$. Ce qui l'intéresse, ce n'est pas le drame compris comme une intrigue pleine de rebondissements et de suspens - puisque la mort des Girondins est annoncée dans le titre même de l'ouvrage - mais le drame de la pensée, le drame intérieur des hommes qui vont à la mort, le drame des politiciens qui voient échouer leur projet pour la république. Puisqu'il n'y a presque pas d'action au sens classique, aristotélicien du terme, toute l'attention du lecteur se concentre sur les caractères (ethos) et le langage (logos) des protagonistes - donc sur leur éloquence.

14 La délibération qui constitue le cœur même du Dernier Banquet concerne l'avenir de la Révolution. Selon Aristote, l'avenir est le temps propre du genre délibératif - on délibère d'une décision à prendre en vue de l'obtention d'un bien ${ }^{41}$. Or, chez Nodier l'emploi du délibératif est paradoxal puisque les Girondins sont conscients que pour eux, il n'y a plus d'avenir sur cette terre. C'est pourquoi à la question de l'avenir 
politique de la France s'adjoint celle de l'avenir de l'homme après la mort. Après les débats politiques, c'est Vergniaud qui dit, en employant une formule proche du langage de la tribune, que « [1]'immortalité de l'âme est décidément la seule question qui reste à l'ordre du jour ${ }^{42}$ ». De fait, pour ces politiciens férus d'éloquence, même le séjour en prison se transforme en une séance parlementaire lors de laquelle différentes factions se heurtent et se disputent. La politique continue à les diviser : il y a ceux qui, comme Vergniaud, sont devenus sceptiques quant à la possibilité d'introduction de la république en France, et ceux qui, comme Brissot, persistent à croire en leur projet politique. Les deux hommes s'affrontent dans une grande joute oratoire dans laquelle deux visions s'opposent : d'un côté c'est le modèle évolutionniste prôné par Vergniaud, et de l'autre, le modèle révolutionnaire défendu par Brissot. Les orateurs ont recours à des définitions ${ }^{43}$, des métaphores ${ }^{44}$, des apophtegmes ${ }^{45}$ et des épigrammes ${ }^{46}$ pour se convaincre mutuellement et fléchir l'adversaire. Le dissensus persiste toutefois: les divisions politiques sont plus fortes que l'imminence de la mort elle-même.

Quoique selon Aristote, dans le genre délibératif, on ne puisse pas débattre de l'impossible ${ }^{47}$, toute l'argumentation de Vergniaud vise à prouver que l'introduction de la république en France relève précisément de l'impossible. Vergniaud parle en politicien désenchanté qui découvre tout juste avant de mourir le tort de sa politique et de sa croyance en une république qui ne s'est avérée qu'une "puérile chimère ${ }^{48}$ ». Tout au long de sa démonstration, il a recours à des allégories soulignant l'inconsistance du projet révolutionnaire : la « déesse » de la liberté est de fait une « furie qui [...] enivre et dévore", l'égalité n'est qu'un lit de Procruste - parce que «[c]e tyran croyait comprendre fort bien l'égalité », la fraternité républicaine n'est autre que celle entre Caïn et Abel ${ }^{49}$.

Ce pessimisme incite les autres convives à la polémique et provoque un vif débat au sujet de l'avenir de la France. Brissot reconnait que les idéaux révolutionnaires sont réalisables avec des peuples fraternels et primitifs, comme celui de l'Amérique. Il s'appuie sur son ethos de voyageur et d'homme politique expérimenté pour affirmer: "Moi, j'ai vu de près les malheurs des peuples, les vices des législations, et l'incurable démence des rois. Je crois, en mon âme et conscience, que la révolution triomphera ${ }^{50}$. " Brissot propose un raisonnement par analogie : si la révolution américaine a réussi, la leur réussira de la même manière parce que la France peut se régénérer par les institutions démocratiques. Dans un langage pondéré et logique, frôlant parfois la tautologie et la naïveté, l'orateur prouve :

J'ai visité des nations innocentes dans leurs mœurs, simples dans leurs besoins, modérées dans leurs ambitions, et par conséquent heureuses de tout le bonheur que peuvent procurer la modération, la simplicité, l'innocence. J'ai compris alors que l'habitude des bonnes institutions fait les bonnes sociétés, et que cette habitude se contracte vite, car celles-là comme celle que nous proposions de fonder, sortaient à peine d'une révolution qui avait éclaté et s'était accomplie en peu d'années sous nos yeux ${ }^{51}$.

Comptant sur son ethos de voyageur et de penseur politique, Brissot reproche au pessimiste Vergniaud son manque d'expérience dans une formule métaphorique: "Vergniaud mourant n'a vu que le berceau d'Hercule ${ }^{52}$." Son adversaire ne lâche cependant pas prise et répond par une nouvelle maxime pleine d'esprit, en détournant la métaphore de Brissot : « Hercule au berceau étouffait des serpents. Il n'en vomissait pas $^{53}$.» Chaque exemple de Brissot qui devait donner de l'espoir aux Girondins est détruit sous le poids de contre-exemples terrassants donnés par Vergniaud. Son 
pessimisme déteint sur les autres condamnés. Ainsi, vers la fin du banquet, Duchâtel tient un long discours pro rege dont on retiendra seulement la péroraison :

Je reconnus sans peine la vérité de ce que Vergniaud nous disait tout à l'heure, du haut d'une autorité qui vaut mieux que la mienne ! Enfants étourdis et mutins, nous avions marché, heureux de traîner derrière nous les lambeaux de nos langes déchirés et de nos lisières rompues; nous nous étions précipités dans l'avenir, sans le prévoir, comme dans une route ouverte; coursiers aveugles et indomptés qui se croyaient attelés au char du monde civilisé, et qui ne traînaient d'abîme en abîme que la claie d'une société suicide. J'ignore ce que vous en pensez, messieurs, mais c'est là ce que nous avons fait !... Les anciennes constitutions de la monarchie que j'ai trop tard étudiées, contenaient mille fois plus d'éléments de liberté qu'il n'en sortirait en mille ans de tous les antres de la Montagne! Et voilà pourquoi je crie : Vive le Roi ${ }^{54}$ !

Nodier, lui-même royaliste à l'époque de l'écriture du Dernier Banquet, ressentait probablement un certain plaisir en convertissant une partie des Girondins à la monarchie. Dans son œuvre, il s'est attaché à représenter les derniers feux de cette éloquence révolutionnaire, à la fois sublime et effrayante, comparable au « chaos [qui] avait enfanté une seconde fois le monde ${ }^{55}$ ». Cette parole a balayé toutes les habitudes discursives de l'Ancien Régime ouvrant ainsi la voie à une nouvelle sensibilité romantique et désenchantée dont Vergniaud est le porte-parole ${ }^{56}$. Pour Nodier, les délibérations politiques ne furent plus jamais aussi belles et pathétiques qu'au moment de la mort des Girondins, ces Athéniens modernes vivant leurs «Thermopyles de la liberté57 ${ }^{27}$. Leur langage et leurs caractères reconstitués grâce à l'imagination de l'écrivain devaient servir d'exemple, en cette année 1833, à la vraie vertu politique, absente selon Nodier de la vie publique sous la monarchie de Juillet qui «manque de passions nobles et de vrais malheurs ${ }^{58}$ ".

Aux yeux de Nodier, Le Dernier Banquet de Girondins n'était qu'une œuvre ratée, l'esquisse d'un drame qu'il n'arrivait pas à écrire à cause de son "impuissance ${ }^{59}$ ", comme il l'affirme dans les paratextes de l'ouvrage. Était-ce donc un exercice de style, une tentative de mise en œuvre d'une éloquence politique qu'il admirait certes, mais qu'il ne savait pas transformer en littérature comme il l'aurait souhaité ? Le drame est resté à l'état d'ébauche, à mi-chemin entre le théâtre et le roman, n'arrivant pas à se dégager du moule de la parole oratoire. Mais est-ce vraiment un défaut? Les expérimentations théâtrales de Sartre, de Beckett ou de Koltès ont habitué le lecteur moderne à goûter cette dramaturgie du huis clos et de l'action centrée uniquement sur la parole. Il est toutefois significatif que pour Nodier, Le Dernier Banquet ne constitue pas vraiment une œuvre littéraire, mais plutôt une "étude historique ${ }^{60}$ » : trop ancré dans la rhétorique du siècle révolu, Le Dernier Banquet fait une pièce à part, qui mérite toutefois sa place au sein de ses très sélectives Æuvres dites complètes.

\section{NOTES}

1. V. Hugo, «Réponse à un acte d'accusation » [1854] dans P. Albouy (dir.), Euvres poétiques II : Les Châtiments, Les Contemplations, Paris, Gallimard, coll. «Bibliothèque de la Pléiade ", 1967, p. 497. 
Sur le sujet de cette déclaration de guerre pour le moins ambivalente, voir P. Laforgue, «Rhétorique et poésie chez Hugo (1822-1855)», dans A. Vaillant (dir.), Écriture, parole, discours: littérature et rhétorique au XIX siècle, Saint-Étienne, Éditions Printer, 1997, p. 63-76.

2. G. Genette, «La rhétorique restreinte », Communications, $n^{\circ} 16,1970$, p. 158-177.

3. Voir F. Douay, «La rhétorique en France au $\mathrm{XIX}^{\mathrm{e}}$ siècle à travers ses pratiques et ses institutions : restauration, renaissance, remise en cause ", dans M. Fumaroli (dir.), Histoire de la rhétorique dans l'Europe moderne, Paris, P.U.F., 1999, p.1071-1214; A. Michel, «Romantisme, littérature et rhétorique », dans M. Fumaroli (dir.), Histoire de la rhétorique dans l'Europe moderne, ouvr. cité, p. 1039-1070 ; A. Vibert, «Fontanier : autour et au-delà la rhétorique dans le premier tiers du XIX siècle ", Revue d'histoire littéraire de la France, $\mathrm{n}^{\circ}$ 105, 2005/2, p. 369-393.

4. La pédagogie rhétorique fondée sur l'imitation des modèles antiques semble caduque et contraire à l'esprit émancipateur des Lumières à un bon nombre d'auteurs (Jean-François Marmontel, Jean-Jacques Rousseau, Jean Le Rond d'Alembert, Antoine Destutt de Tracy). J'ai traité plus amplement de ce sujet dans mon livre Éloquences romantiques. Les années de l'Arsenal (1824-1834), Poznań/Champs-sur-Marne, Wydawnictwo Naukowe UAM \& LISAA éditeur, 2021, p. 30-46. URL : <https://books.openedition.org/lisaa/1567>.

5. Voir B. Schlieben-Lange et J. Hafner, «Rhétorique et Grammaire générale dans les Écoles centrales ", dans J.- P. Sermain et É. Négrel (dir.), Une Expérience rhétorique. L'éloquence de la Révolution, Oxford, Voltaire University Foundation, 2002, p. 231-244.

6. Voir F. Douay-Soublin, « La rhétorique en Europe à travers son enseignement », dans S. Auroux (dir.), Histoire des idées linguistiques, Liège, Mardaga, 1992, p. 467.

7. Pour plus de détails sur ces différents aspects de la redéfinition romantique de l'éloquence, on consultera la bibliographie dans mon ouvrage Éloquences romantiques (ouvr. cité).

8. Voir G. Venzac, Les Premiers Maîtres de Victor Hugo, Paris, Bloud et Gay, 1955, p. 300-301. Pour plus de détails sur le programme de la classe de rhétorique, voir F. Douay, «La rhétorique en France au XIX ${ }^{\mathrm{e}}$ siècle... », art. cité et A. Vibert, art. cité.

9. Cité par M. Le Yaouanc, «Balzac au lycée Charlemagne et dans les pensions du Marais (1815-1816) », Année balzacienne, $\mathrm{n}^{\circ}$ 3, 1962, p. 71.

10. Voir P. de Musset, Biographie d'Alfred de Musset, sa vie et ses œuvres, Paris, Charpentier, 1877, p. 54 ainsi que Frank Lestringant, Alfred de Musset, Paris, Flammarion, 1999, p. 50.

11. Voir A. Hugo, Victor Hugo raconté par un témoin de sa vie, Paris, Librairie Internationale, 1863, t. I, p. 191-197.

12. L'expression vient de J.-L. Diaz, Devenir Balzac, Paris, Pirot, 2007, p. 25.

13. H. de Balzac, «La Peau de chagrin » [1831], dans M. Bouteron (dir.), La Comédie humaine, IX, Études philosophiques, I, Paris, Gallimard, coll. «Bibliothèque de la Pléiade », 1950, p. 165. Il s'agit de Charles Rollin, auteur du Traité des études (1726-1728).

14. Voir C.-A. Sainte-Beuve, «Le Cénacle" [1829], dans Vie, Poésies et Pensées de Joseph Delorme, Paris, Michel Lévy Frères, 1863, p. 67.

15. V. Hugo, « Ce qui se passait aux Feuillantines vers 1813 » [Les Rayons et les Ombres, 1840], dans P. Albouy (dir.), Euvres poétiques de Victor Hugo, Paris, Gallimard, coll. «Bibliothèque de la Pléiade » 1964, t. I, p. 1064.

16. C. Nodier, "La Légende de sœur Béatrix », dans P.-G. Castex (dir.), Contes de Nodier, Paris, Garnier, 1961, p. 781-782.

17. Sur ce sujet, voir C. Saminadayar, " “...Et tords-lui son cou” : exorcismes vallésiens », dans A. Vaillant (dir.), Écriture, parole, discours: littérature et rhétorique au XIX siècle, ouvr.cité, p. 139-156.

18. C. Nodier, «Recherches sur l'éloquence révolutionnaire ", dans CEuvres complètes de Charles Nodier, t. VII, Paris, Renduel, 1833, p. 324-325. 
19. Voir J. Larat, La Tradition et l'exotisme dans l'œuvre de Charles Nodier, Paris, Champion, 1923, p. 35-39.

20. Nodier raconte son expérience de la Terreur dans Souvenirs, épisodes et portraits pour servir à l'histoire de la Révolution et de l'Empire, Paris, Alphonse Levavasseur, 1831, t. I.

21. Au sujet de ce traité, voir É. Négrel, «1799: L'Essai sur l'art oratoire de Joseph Droz », Le dixhuitième siècle, $\mathrm{n}^{\circ} 35$ (L'épicurisme des Lumières), 2003, p. 499-518.

22. Sur ce sujet, voir J.-P. Sermain, « Une révolution dans l'expression verbale des émotions : L'art de parler de Bernard Lamy », Littératures classiques, $\mathrm{n}^{\circ} 68$ (Les émotions publiques et leurs langages à l'âge classique), 2009, p. 203-210.

23. Voir notamment J.-J. Rousseau, Émile [1762], dans R. Trousson et F. S. Eigeldinger (dir.), Euvres complètes de Jean-Jacques Rousseau, t. VII, Paris, Honoré Champion, 2012, p. 651 et passim.

24. C. Nodier, Cours de belles-lettres, tenu à Dole de juillet 1808 à avril 1809, éd. d'A. Barraux, Genève, Droz, 1988, p. 35.

25. Cette opposition entre le précepte théorique - de moindre valeur - et l'exemple donné par une œuvre d'éloquence ou de poésie ouvre le Cours de belles-lettres de Nodier (ibid., p. 33). Ce mépris pour la théorie littéraire caractérise un bon nombre de romantiques (Vigny, Musset, Hugo). J'ai traité plus amplement de cette matière dans mon livre Éloquences romantiques..., ouvr. cité, p. 65-72.

26. C. Nodier, Cours de belles-lettres, ouvr. cité, p. 60.

27. Nodier cite le Traité des tropes de Dumarsais dès le « Discours inaugural » qui ouvre son cours (ibid., p. 33-34). Par la suite, il analyse brièvement la formation de la parole, la composition des mots et quelques éléments de grammaire. Il avoue que la « partie philosophique de la grammaire [était] depuis longtemps l'objet de [s]es études les plus assidues" (ibid., p. 36). Voir aussi ibid., p. 47-49.

28. Ibid., p. 63.

29. Voir ibid., p. 65.

30. Nodier se contente de quelques définitions des figures de mots les plus connues (comparaison, métaphore, métonymie, allégorie etc.) mais aussi de quelques figures de pensée (concession, anticipation, interrogation) ibid., p. 54-58.

31. Ibid., p. 69.

32. J'ai traité plus amplement de ce sujet dans l'article «L'éloquence révolutionnaire dans les articles de presse de Charles Nodier au tournant des années 1830 ", Cahiers d'études nodiéristes, $\mathrm{n}^{\circ} 4$ (Charles Nodier et la presse de son temps), 2017/2, p. 65-91.

33. Nodier peut se permettre d'aborder ce sujet parce que son cours n'a pas été prévu pour la publication - il nous est parvenu grâce aux notes de l'un des auditeurs, Charles-Augustin Dusillet, et il a paru seulement au $\mathrm{xx}^{\mathrm{e}}$ siècle dans l'édition d'Annie Barraux déjà citée. Le manuscrit des notes de Charles-Augustin Dusillet, est disponible sur le site des archives municipales de Dôle (<https://patrimoine-archives.grand-dole.fr/>).

34. C. Nodier, Cours de belles-lettres, ouvr. cité, p. 68.

35. C. Nodier, Le Dernier Banquet des Girondins, dans CEuvres complètes de Charles Nodier, t. VII, ouvr. cité, p. 16.

36. Nodier parle lui-même d'une "alliance un peu adultère du drame et de l'histoire » (Euvres complètes de Charles Nodier, t. VII, p. 9-10). Sur ce sujet, voir G. Zaragoza, «Le Dernier Banquet des Girondins. Étude ou scène historique ? ", Cahiers d'études nodiéristes, $\mathrm{n}^{\circ} 9$, (" Une alliance adultère », scène historique et poème dramatique, ou le théâtre sans la scène [1747-1833]), 2020/1, p. 125-144.

37. La partie théâtrale est toutefois précédée et close par le récit du narrateur. Dans l'introduction, il décrit minutieusement les personnages de son drame, en se focalisant sur leur démarche et leur manière de parler. L'éloquence du geste et de la pose - l'actio oratoire - est donc confinée dans la partie narrative, en absence de didascalies dans la partie dramatisée. 
38. Selon toute probabilité, ce banquet n'eut pas lieu mais le mythe du dernier repas des Girondins «figurait au nombre des croyances les plus répandues, les mieux partagées de l'imaginaire de la Révolution" au XIX siècle (V. Robert, Le Temps des banquets. Politique et symbolique d'une génération (1818-1848), Paris, Éditions de la Sorbonne, 2010, p. 335). Lamartine, Thiers, Dumas, Michelet et d'autres encore ont également écrit sur ce banquet mythique.

39. C. Nodier, Le Dernier Banquet des Girondins, ouvr. cité, p. 10.

40. Ibid., p. 9. À la fin de l'œuvre, il adjoint une volumineuse section des notes historiques dans lesquelles il présente ses sources (témoignages oraux, articles de presse, séances à la tribune).

41. Aristote, Rhétorique, trad. par M. Dufour, Paris, Les Belles Lettres, 1991, t. I, p. 44.

42. C. Nodier, Le Dernier Banquet des Girondins, ouvr. cité, p. 123.

43. L'état de définition est un des moyens de mener une controverse ; sur ce sujet voir B. Sans, «Exercer l'invention ou (ré)inventer la controverse », Exercices de rhétorique, $\mathrm{n}^{\circ} 5$ (« Rhétorique et citoyenneté »), 2015. Disponible sur <http://journals.openedition.org/rhetorique/404> [consulté le 30/01/2021]. Dans le Dernier Banquet, c'est Vergniaud qui a recours à l'état de définition dans une longue réplique dans laquelle, grâce à la multiplication des définitions du concept de « république », il démontre l'impossibilité de mener à bien un projet politique sur la signification duquel personne ne peut s'entendre (Le Dernier Banquet des Girondins, ouvr. cité, p. 118).

44. On note surtout l'abondance des métaphores naturelles dans le discours sur la Révolution. Elles sont malléables et réversibles : autant pour Vergniaud, la république en France est une fleur sans tige (puisqu'elle n'est pas enracinée dans le sol des institutions et des mœurs de la nation), autant Brissot soutient qu'on peut la transplanter sur le sol français comme on transplante des plantes rares ; voir ibid., p. 77, 82-83.

45. Parmi les plus célèbres, on note celles de Vergniaud comme «La révolution est comme Saturne. Elle dévorera tous ses enfants » (ibid., p. 76).

46. Ce sont aussi les autres Girondins qui lancent les épigrammes - par exemple Gensonné, ibid., p. 69.

47. Aristote, Rhétorique, t. I, ouvr. cité, p. 86.

48. C. Nodier, Le Dernier Banquet des Girondins, ouvr. cité, p. 73.

49. Ibid., p. 74-75.

50. Ibid., p. 76. Ou encore, avec le même rappel éthique : «Je te parle avec cette connaissance plus calme et plus approfondie des hommes et des événements que l'âge, la méditation et les voyages m’ont donné » (ibid., p. 77).

51. Ibid., p. 77.

52. Ibid., p. 77.

53. Ibid., p. 77.

54. Ibid., p. 115.

55. C. Nodier, «De la littérature pendant la Révolution. Éloquence de la tribune : la Gironde », Revue de Paris, 1829, tome V, p. 6.

56. J'ai traité plus amplement de ce sujet dans mon ouvrage Éloquences romantiques, ouvr. cité, p. 75-79.

57. C. Nodier, Le Dernier Banquet des Girondins, ouvr. cité, p. 12.

58. C. Nodier, « De la prose française, et de Diderot », dans J.-R. Dahan (dir.), Feuilletons du Temps. Tome I - Articles et feuilletons (1830-1843), Paris, Classiques Garnier, 2010, p. 677.

59. Nodier revient à cet aveu d'échec dans ses Recherches sur l'éloquence révolutionnaire, publiées dans le même volume VII de ses Euvres complètes, où il constate que « ces recherches n'étaient effectivement que des études pour un livre que je concevais en le commençant sous un autre aspect beaucoup plus riche en développements. J'ai déjà dit, mais je ne le repérerai jamais assez, que mon impuissance m'avait détrompé de cette longue illusion» (Recherches sur l'éloquence révolutionnaire, CEuvres de Charles Nodier, ouvr. cité, t. VII, p. 225). Les Recherches quant à elles ne 
sont d'après Nodier qu'une « glose de ce drame imparfait que j'ai intitulé : Le Dernier Banquet des Girondins. » (ibid., p. 226).

60. L'ouvrage porte un sous-titre: «Étude historique suivie des Recherches sur l'éloquence révolutionnaire ».

\section{RÉSUMÉS}

Après une profonde remise en cause de la rhétorique pendant les Lumières et la Révolution française, le début du xIX ${ }^{\mathrm{e}}$ siècle signe une renaissance de cette discipline et sa réintégration dans le cursus scolaire. Les écrivains romantiques reçurent une excellente éducation rhétorique qui a laissé une trace profonde sur leurs œuvres littéraires. Les écrits de Charles Nodier, orateur révolutionnaire, professeur d'éloquence qui fut aussi l'un des pères du romantisme français, témoignent comment la rhétorique informait la littérature des années 1830. Dans son Dernier Banquet des Girondins, Nodier exploite savamment la topique du genre délibératif pour dépeindre un des moments climatériques de l'éloquence révolutionnaire qui, selon lui, donna naissance à la sensibilité et la littérature romantiques.

After the profound crisis in the aftermath of the Enlightenment and the French Revolution, the beginning of the $19^{\text {th }}$ century marked the rebirth of rhetoric and its reintroduction into the school curriculum. The French Romantic writers received an excellent rhetorical education, which left a deep mark on their literary works. Among the fathers of French Romanticism, Charles Nodier was a revolutionary orator and professor of eloquence whose works bear witness to how rhetoric informed the literature of the 1830s. In his Last Banquet of the Girondins, Nodier exploits the rhetorical topic of the deliberative genre to depict one of the climactic moments of revolutionary eloquence, which, according to him, gave birth to romantic sensibility and literature.

\section{INDEX}

Mots-clés : romantisme, genre délibératif, Charles Nodier, Le Dernier Banquet des Girondins, Révolution française

Keywords : romanticism, deliberative genre, Charles Nodier, Le Dernier Banquet des Girondins, French Revolution

\section{AUTEUR}

\section{MARTA SUKIENNICKA}

Université Adam Mickiewicz de Poznań

Marta Sukiennicka est maîtresse de conférences en littérature française à l'université Adam Mickiewicz (Pologne). Ses recherches portent sur l'histoire de la rhétorique, l'œuvre de Charles Nodier et les rapports entre la littérature et les sciences du vivant au XIX $\mathrm{X}^{\mathrm{e}}$ siècle. Sa thèse Éloquences romantiques. Les années de l'Arsenal (1824-1834) est parue en 2021 dans une coédition 
franco-polonaise (UAM \& LISAA éditeur, coll. « Savoirs en texte »). Elle a codirigé avec

Émilie Pézard l'ouvrage Autour de Jean Sbogar de Charles Nodier. Le bicentenaire d'un roman majeur du romantisme (2019). 